\title{
Dye-Sensitized Solar Cell Based on Polyaniline/Multiwalled Carbon Nanotubes Counter Electrode
}

\author{
Shaker Ebrahim, ${ }^{1}$ Moataz Soliman, ${ }^{1}$ M. Anas, ${ }^{2}$ Mostafa Hafez, ${ }^{1}$ and Tarek M. Abdel-Fattah ${ }^{3}$ \\ ${ }^{1}$ Department of Materials Science, Institute of Graduate Studies and Research, Alexandria University, P.O. Box 832, Shatby, \\ Alexandria 21526, Egypt \\ ${ }^{2}$ Physics Department, Faculty of Science, Alexandria University, Moharram Bek, Alexandria 21511, Egypt \\ ${ }^{3}$ Applied Research Center, Jefferson National Lab and Department of Molecular Biology and Chemistry, Christopher Newport \\ University, Newport News, VA 23606, USA
}

Correspondence should be addressed to Shaker Ebrahim; shebrahim@alex-igsr.edu.eg

Received 16 May 2013; Revised 30 August 2013; Accepted 30 August 2013

Academic Editor: Fahrettin Yakuphanoglu

Copyright (C) 2013 Shaker Ebrahim et al. This is an open access article distributed under the Creative Commons Attribution License, which permits unrestricted use, distribution, and reproduction in any medium, provided the original work is properly cited.

This work presented the successful fabrication of dye-sensitized solar cell using polyaniline base (EB), multiwalled carbon nanotubes (MWCNTs), organic dye (rhodamine $\mathrm{B}$ or riboflavin), zinc oxide ( $\mathrm{ZnO}$ ), and indium tin oxide (ITO). The electrical properties of the resultant devices were investigated by measuring the current density voltage $(J-V)$, capacitance voltage $(C-V)$, and impedance measurements under both dark and illuminated conditions. The photovoltaic cell characteristics, that is, open circuit voltage $\left(V_{\text {oc }}\right)$, short circuit current density $\left(J_{\mathrm{sc}}\right)$, and energy conversion efficiency $(\eta)$, were evaluated under illumination and were found to be $0.48 \mathrm{~mA} / \mathrm{cm}^{2}, 400 \mathrm{mV}$, and $0.224 \%$, respectively, for ITO/EB-MWCNTs/ZnO-rhodamine B/ITO heterostructure. Using impedance spectra, it was found that the series resistances of this type of solar cell are 62 and $60 \Omega$ under darkness and illumination, respectively.

\section{Introduction}

Conjugated polymers such as polyaniline (PANI) were used in organic solar cells due to their excellent electrochemical optical properties and environmental stability. Unlike all other conducting polymers, the conductivity of PANI can be tuned by varying the degree of oxidation and the degree of protonation [1]. Also, by incorporating other additives to a PANI layer, its electrical conductivity can be improved. Carbon nanotubes (CNTs) have shown significant potential; they can be used in a wide variety of applications on the basis of their remarkable mechanical and electronic properties [2-6]. CNTs have highly $\pi$-conjunctive and hydrophobic sidewalls consisting of $\mathrm{sp}^{2}$ carbons [7], which enable them to be incorporated into organic solar cells. Recently, there has been a large interest in incorporating carbon nanotubes (CNTs) into organic solar cells because of their unique electrical properties of CNTs. For example, CNTs were used as electron acceptors in the photoactive layer of the solar cells [8]. Also, CNTs were used as transparent anodes in order to replace the prevailing and widely used indium tin oxide (ITO).

DSSC with structure of PANI/MWCNT composite films with different MWNT concentrations and $\mathrm{TiO}_{2}$ nanocrystals showed a conversion efficiency of 6\% [9]. PANI/graphene counter electrode (CE) prepared by in situ polymerization of aniline monomer in graphene dispersion for a DSSC showed a conversion efficiency of $6.09 \%$ comparable to that of a cell with a Pt CE [10]. The DSSCs assembled with the prepared pulsed PANI CE exhibited an enhanced photovoltaic conversion efficiency of 5.19\% [11]. The DSSCs assembled with the pulsed PANI/multiwalled carbon nanotubes (MWCNT) CE exhibited the superior photovoltaic conversion efficiency of $6.24 \%$ (compared to $5.18 \%$ for DSSCs with PANI CE or 6.05\% for DSSCs with Pt CE) [12].

A dye-sensitized solar cell based on polyaniline base (EB), single-walled carbon nanotubes, organic dyes (rhodamine B and/or riboflavin), zinc oxide ( $\mathrm{ZnO}$ ), and indium tin oxide (ITO) was successfully fabricated in our previous work [13]. The photovoltaic cell parameters, that is, open circuit voltage 
$\left(V_{o c}\right)$, short circuit current density $\left(J_{s c}\right)$, and energy conversion efficiency $(\eta)$, were evaluated under illumination $(0.09$ $\mathrm{W} / \mathrm{cm}^{2}$ ) and are found to be $0.777 \mathrm{~V}, 0.484 \mathrm{~mA} / \mathrm{cm}^{2}$, and $0.462 \%$, respectively for ITO/EB-SWCNTs/ZnO-rhodamine $\mathrm{B} / \mathrm{ITO}$ structure. The sensitization of $\mathrm{ZnO}$ using a mixture of rhodamine $\mathrm{B}$ and riboflavin dyes doubled the values of both $J_{\mathrm{sc}}$ and $\eta$ [13]. The aim of this work is to fabricate dye-sensitized solar cell based on EB, multiwalled carbon nanotube (MWCNT), rhodamine B and riboflavin dyes, and $\mathrm{ZnO}$ components. The current voltage, capacitance voltage, and impedance measurements were measured under both darkness and illumination to evaluate and compare the electronic parameters of this type of solar cells.

\section{Experimental Work}

2.1. Preparation of EB. Aniline $(0.2 \mathrm{M})$ was added to $0.2 \mathrm{M}$ hydrochloric acid and mixed with $0.25 \mathrm{M}$ ammonium peroxydisulfate. The EB precipitate was collected on a filter and washed with three $100 \mathrm{~mL}$ portions of $0.2 \mathrm{M} \mathrm{HCl}$ and with acetone. Polyaniline (emeraldine) hydrochloride powder was air-dried and then dried in a vacuum at $60^{\circ} \mathrm{C}$. Additional polymerizations were carried out in an ice bath at $0^{\circ} \mathrm{C}$. Ammonia solution (3\%) was added to the polyaniline hydrochloride for 2 hours with continuous stirring to obtain the polyaniline base (EB). The deprotonated polyaniline was then separated, washed, and dried.

2.2. Preparation of $\mathrm{ZnO}$ Nanoparticles. The $\mathrm{ZnO} N P s$ powder was prepared as follows: $100 \mathrm{~mL}$ of a methanol-based, $0.1 \mathrm{M} \mathrm{NaOH}$ solution was first heated to $65^{\circ} \mathrm{C}$ and $2.19 \mathrm{~g}$ of zinc acetate dihydrate was then added under constant stirring until a transparent solution formed. $50 \mathrm{~mL}$ of distilled water was then added to precipitate the ZnO NPs powder. The resulting powder was washed with distilled water then dried in an oven at $150^{\circ} \mathrm{C}$ for $12 \mathrm{~h} \mathrm{[14].}$

2.3. Preparation of MWCNTs. The MWCNTs used in this study were fabricated by the catalytic decomposition of methane on iron-based catalysts [15]. The reaction took place in a quartz tube. Under an argon flow, the furnace was heated to the reaction temperature of $950^{\circ} \mathrm{C}$. In the step of catalyst reduction $(10 \mathrm{~min})$, argon was replaced by hydrogen $\left(1000 \mathrm{~cm}^{3} \mathrm{~min}^{-1}\right)$. In the growth process, methane replaced the hydrogen flow. The reactor was then cooled to an ambient temperature under argon flow. The MWCNTs were purified by refluxing the MWCNTs in $2.0 \mathrm{M}$ nitric acid for $5 \mathrm{~h}$, followed by centrifugation, filtration, and drying in a $100^{\circ} \mathrm{C}$ vacuum.

2.4. Fabrication of Dye-Sensitized Solar Cell Based on EB and $M W C N T$. The colloidal solution of $\mathrm{ZnO}$ in small amount of deionized water was coated onto ITO using manual applicator with controlled thickness to be $30 \mu \mathrm{m}$. The ITO glass substrate was covered on two parallel edges with adhesive tape to provide noncoated areas for electrical contact. The $\mathrm{ZnO}$ electrode was sintered for $30 \mathrm{~min}$ at $250^{\circ} \mathrm{C}$ in air. EB $(20 \mathrm{mg}$ ) was dissolved in $10 \mathrm{~mL}$ DMF and MWCNTs (10 mg)

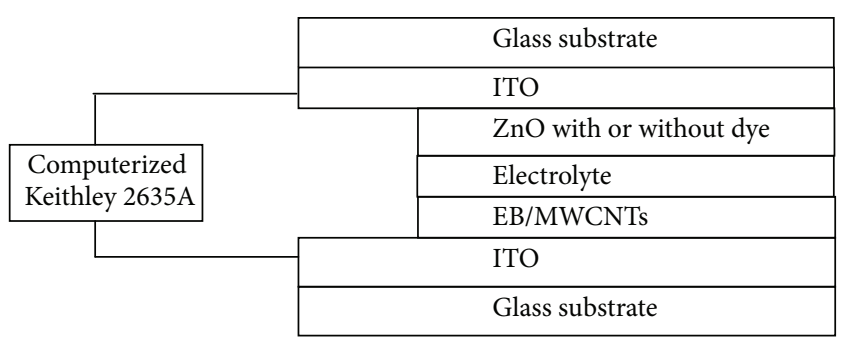

Scheme 1: Schematic diagram of the fabricated dye-sensitized solar cell based on EB-MWCNTs composite counter electrode.

was also added to EB solution and a sonication for the mixed solution for 30 min was carried out. EB with MWCNT solution was cast onto ITO with $10 \mu \mathrm{m}$ and dried at $60^{\circ} \mathrm{C}$ for $30 \mathrm{~min}$. The fabrication of dye-sensitized solar cell was fabricated by sandwiching the sensitized $\mathrm{ZnO}$ photoanode with ITO/EB-MWCNT CE using paper clips without an additional pressure. The potassium iodide $(0.5 \mathrm{M})$ and iodine $(0.05 \mathrm{M})$ as an electrolyte solution in ethanol was inserted between the two electrodes. The riboflavin and/or rhodamine B dyes $(0.05 \mathrm{M})$ in $20 \%(\mathrm{v} / \mathrm{v})$ acetonitrile in water and ethanol, respectively, were used to sensitize the $\mathrm{ZnO}$ electrode. The fabricated design of the dye-sensitized solar cell fabricated based on EB-MWCNTs composite, $\mathrm{ZnO}$, and dye and ITO is shown in Scheme 1.

2.5. Characterization and Measurement Techniques. UVvisible spectra for $\mathrm{EB}$, riboflavin or rodamine $\mathrm{B}$ dyes dissolved in DMF, water/acetonitrile, and methanol, respectively, were obtained using a Thermo Evolution 600 UV-visible spectrophotometer. Current voltage characteristics were measured both in the darkness and under illumination using a computerized Keithley 2635A system source meter. The level of illumination provided was calibrated using a Solarex standard solar cell. The Mott-Schottky plots under darkness and illumination were measured using a Gamry G750 potentiostat/galvanostat with pilot integration operating with EIS300 software at $100 \mathrm{~Hz}$ and room temperature. Impedance measurements under darkness and different illumination at zero bias were mainly performed in a frequency range of $0.1 \mathrm{~Hz}$ to $0.30 \mathrm{MHz}$. The amplitude of the sinusoidal $10 \mathrm{mV}$ voltage signal was used.

\section{Results and Discussion}

3.1. UV-Visible Spectra. The UV-visible spectra of EB, riboflavin or rhodamine B dyes dissolved in DMF, acetonitrile/water, and ethanol, respectively, are shown in Figure 1. The EB shows absorption peaks near $600 \mathrm{~nm}$, which are due to electronic excitation from the highest occupied molecular orbital (HOMO, $\pi_{b}$ ) of benzoid part to the lowest unoccupied molecular orbital (LUMO, $\pi_{q}$ ) of quinoid ring. Peaks at $350 \mathrm{~nm}(3.788 \mathrm{eV})$ for $\mathrm{EB}$ are attributed to two different transitions: the $\pi \rightarrow \pi^{*}$ transition and a transition from lowlying orbitals to the $\pi_{q}$ orbital [16]. The shoulder observed at $420 \mathrm{~nm}$ for EB may be attributed to the formation of 


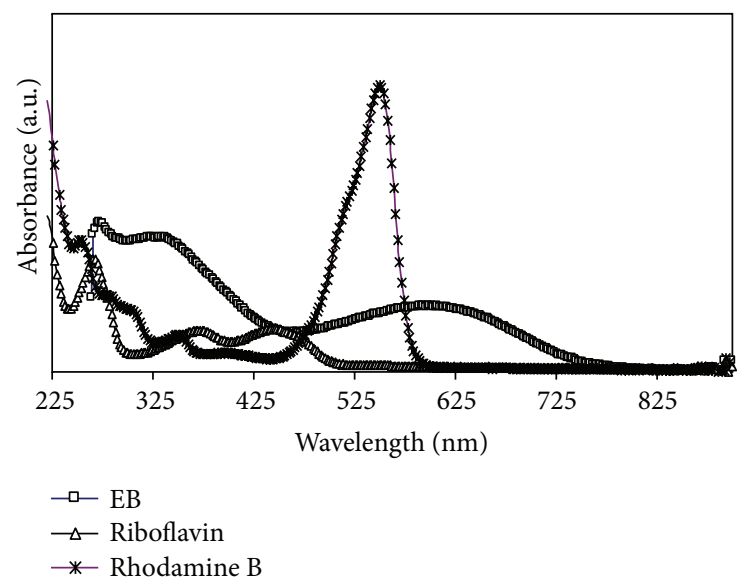

FIGURE 1: UV-visible spectra of EB, riboflavin, and rodamine B dyes.

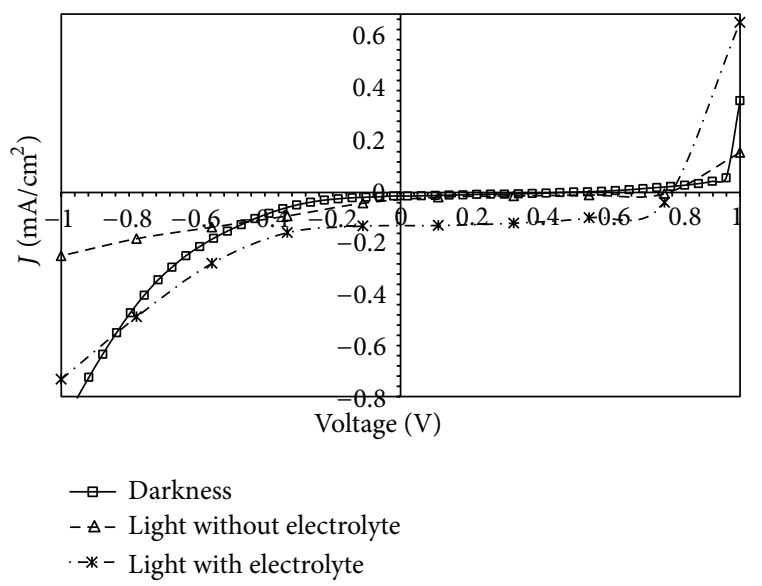

FIGURE 2: $J-V$ curves of ITO/EB-MWCNT/ZnO-riboflavin/ITO structure under darkness and illumination and with and without electrolytes.

delocalized polarons. It is indicated that the presence of a low doping level for EB during the spinning process may be a result of atmospheric oxygen [17]. A conventional riboflavin is known to have two characteristic absorption bands at ca. 370 and $444 \mathrm{~nm}$ for its oxidized form in the visible range [18]. Rhodamine B shows the main characteristic electronic absorption band at $540 \mathrm{~nm}$ in the visible region assigned to $n-\pi^{*}$ transition.

3.2. J-V Characteristics. Figure 2 shows the effect of sensitization of $\mathrm{ZnO}$ with riboflavin dye on the $J-V$ characteristic curves in darkness and illumination and with and without electrolyte. The structure of ITO/EB-MWCNT/ZnOriboflavin/ITO has high $V_{\text {oc }}(0.8)$, low $J_{\text {sc }}\left(0.131 \mathrm{~mA} / \mathrm{cm}^{2}\right)$, and an $\eta$ of (0.137). The electrolyte enhances the photovoltaic parameters because it can act as electron mediator between photoelectrode and CE. Due to the internal electric field, the excited electrons can then transfer to the other side of the cell via the external circuit giving output current.

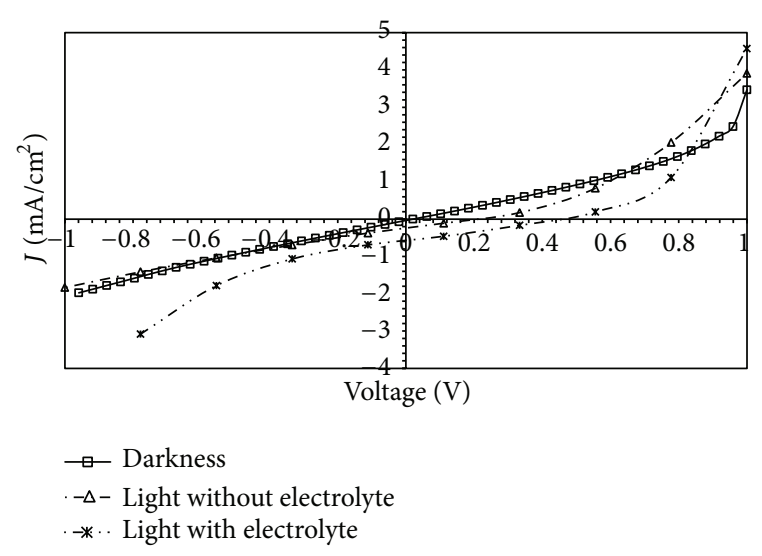

FIGURE 3: $J-V$ characteristics curves of ITO/EB-MWCNT/ZnOrhodamine B/ITO structure in darkness and illumination and with and without electrolytes.

However, the small value of efficiency $\eta$ may be due to low absorbance intensity of riboflavin. $V_{\text {oc }}$ value depends on the difference between the Fermi level of the electron in $\mathrm{ZnO}$ and the cathodic potential of the redox couples on the CEs. Due to the high electrochemical activities of the CE based on EB/MWCNTs CE, it possesses relatively high $V_{\text {oc }}$ values $(\sim 0.80 \mathrm{~V})$, comparable to that of the Pt CE $(0.74 \mathrm{~V})[11,12]$. The performance of this DSSC is lower than that obtained previously using of CE with EB-SWCNTS [13].

Figure 3 investigates the effect of sensitization of $\mathrm{ZnO}$ with rhodamine $\mathrm{B}$ dye on the $J-V$ characteristic curves in darkness and illumination and with and without electrolytes. For this dye-sensitized solar cell structure of ITO/EBMWCNTs/ZnO-rhodamine, B/ITO has a $V_{\text {oc }}, J_{\text {sc }}$, and $\eta$ equal to $0.4 \mathrm{~V}, 0.48 \mathrm{~mA} / \mathrm{cm}^{2}$, and 0.224 , respectively. This enhancement in performance is due to the sensitization effect of rhodamine $\mathrm{B}$ dye for $\mathrm{ZnO}$. It was known that the role of $\mathrm{EB}$ can be used as a hole transport material [16]. MWCNTs also can be used as a hole collection. In addition, MWCNTs offer extremely high surface areas and a tremendous opportunity for exciton dissociation. Durrant et al. compared the electron injection and charge recombination of ruthenium and tetrakis (4-carboxyphenyl)porphyrins on $\mathrm{TiO}_{2}$. They stated that the high efficiency reported for ruthenium dye probably originates from differences in the rate of electron transfer to the dye cation from the electrolyte. They also estimated that the lower efficiency of porphyrin sensitizers results from the increased probability of exciton annihilation from close porphyrin proximity [19]. Dissociation of exciton to electron and hole often occurs at the interface between materials of high electron affinity and low ionization potential. It is known that CNTs can act as electron transport materials [20]. The possibility of enhancing exciton dissociation and electron transport through the percolating carbon nanotubes to the negative electrode has been shown by Kymakis and Amaratunga [21].

Schematic energy diagram of this type of DSSC is shown in Scheme 2. The following primary steps convert photons to current [22]. 


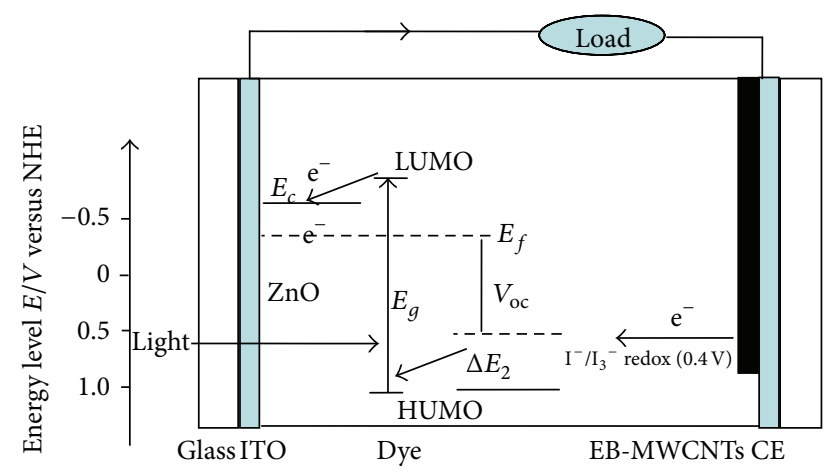

Scheme 2: Photocurrent mechanism of ITO/EB-MWCNTs/ZnOriboflavin/ITO.

(1) Riboflavin dye adsorbed on the $\mathrm{ZnO}$ surface absorbs incident photon flux.

(2) The excited electrons from excited dye are injected into the conduction band of the $\mathrm{ZnO}$ electrode, resulting in the oxidation of dye.

(3) Injected electrons in the conduction band of $\mathrm{ZnO}$ are transported between $\mathrm{ZnO}$ nanoparticles with diffusion toward the back contact and consequently reach the counter electrode through the external load and wiring.

(4) The oxidized dye accepts electrons from the $\mathrm{I}^{-}$ion redox mediator, regenerating the ground state, and $\mathrm{I}^{-}$ is oxidized to the oxidized state, $\mathrm{I}_{3}{ }^{-}$.

(5) The oxidized redox mediator, $\mathrm{I}_{3}{ }^{-}$, diffuses toward the counter electrode and is re-reduced to $\mathrm{I}^{-}$ions. Further investigations will be carried out to study the main factors that contribute to improving the performance of this type of DSSC.

3.3. C-V Characteristics. Figure 4 illustrates Mott-Schottky plots for of ITO/EB-MWCNT/ZnO-riboflavin/ITO structure under darkness and illumination with electrolytes. The reverse bias capacitance measurements are made at high frequency $(100 \mathrm{~Hz})$ such that the interface states are unable to respond to the ac signal. It is noted that $1 / C^{2}$ versus $V$ plots decrease in the negative bias region whereas in the positive bias region, the capacitance becomes steadily constant. This linear relationship between $1 / C^{2}$ and reverse voltage indicates the formation of heterojunction [23]. The capacitance $(C)$ of this type of DSSC in the ideal case can be expressed as [24,25]

$$
\frac{1}{C^{2}}=\frac{2\left[V_{d}+V\right]}{q \varepsilon_{o} \varepsilon_{s} N S},
$$

where $V$ is the applied potential, $S$ is the active device area, $N$ is the carrier concentration, $V_{d}$ is the diffusion potential, $\varepsilon_{o}$ is the permittivity of vacuum, and $\varepsilon_{s}$ is the relative dielectric constant of EB. According to simple theory, the capacitance for low reverse bias voltages is dominated by the depletion region of the semiconductor and the $\left(1 / C^{2}-V\right)$ graph should give a straight line. The change in slope in

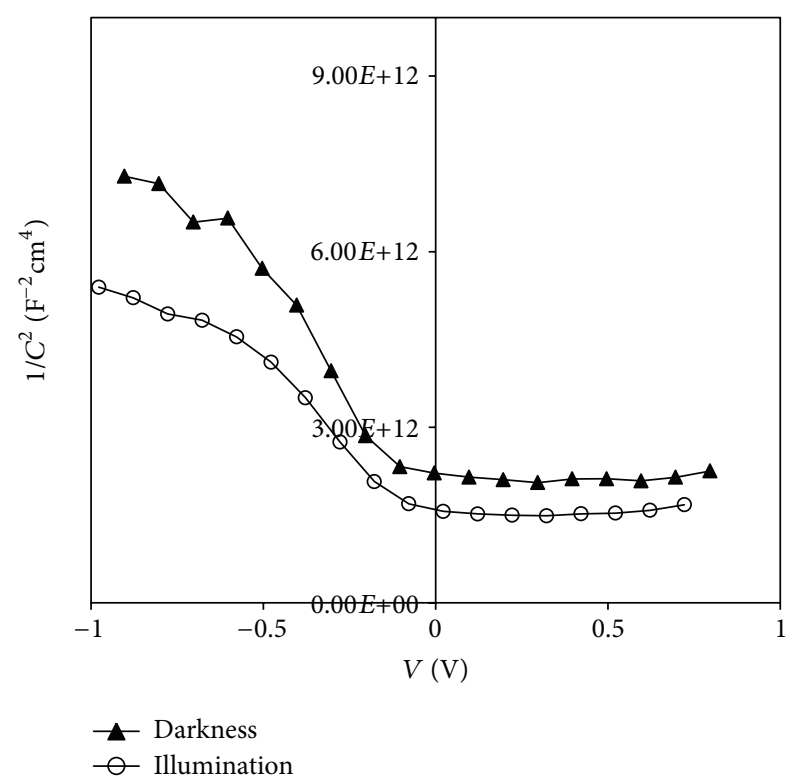

Figure 4: $C-V$ curves of ITO/EB-MWCNT/ZnO-riboflavin/ITO structure under darkness and illumination.

the plots of near zero bias could be interpreted as a change in the spatial distribution of the acceptor ions. The nonlinearities express either an excess capacitance or inductive reactance. The carrier concentrations can be determined from the slope of $C^{-2}$ versus $V$ plots. It is found that the orders of carrier concentrations of ITO/EB-MWCNT/ZnOriboflavin/ITO under darkness and illumination are $1 \times 10^{12}$ and $5 \times 10^{12} / \mathrm{cm}^{3}$, respectively. These low concentrations of charge carriers explain the low value of $J_{\text {sc }}$ and efficiency of the heterojunctions. It is apparent that the capacitance of a junction generally increases with illumination. Thus, this is a consequence of reduced depletion width and built-in potentials, or diffusion potentials, under light [26].

Figure 5 shows Mott-Schottky plots for of ITO/EBMWCNT/ZnO-rhodamine B/ITO structure under darkness and illumination with electrolytes. The appearance of a linear region in the forward bias is due to the reverse roles in the polarity between the EB-MWCNT electrode and $\mathrm{ZnO}$ rhodamine B. Further studies will be carried out to understand this new phenomenon. It is found that the order of carrier concentration of this structure is $10^{15} / \mathrm{cm}^{3}$. This higher concentration of charge carrier explains the improvement in the value of $J_{\mathrm{sc}}$ and efficiency of this heterojunction.

3.4. Impedance Spectroscopy. The impedance analysis method enables the reliable determination of series resistance, shunt resistance, saturation current, and built-in potential of nonideal semiconductor $\mathrm{p}-\mathrm{n}$ junctions $[16,27-$ 29]. Impedance spectroscopy is a technique for electrical characterization by measuring the response of materials to an applied ac signal. According to this technique, the complex impedance of the test sample $Z$, which is expressed as $Z=Z^{\prime}-j Z^{\prime \prime}$, where $Z^{\prime}$ is the real part and $Z^{\prime \prime}$ the imaginary part, is measured directly in the frequency domain. The 


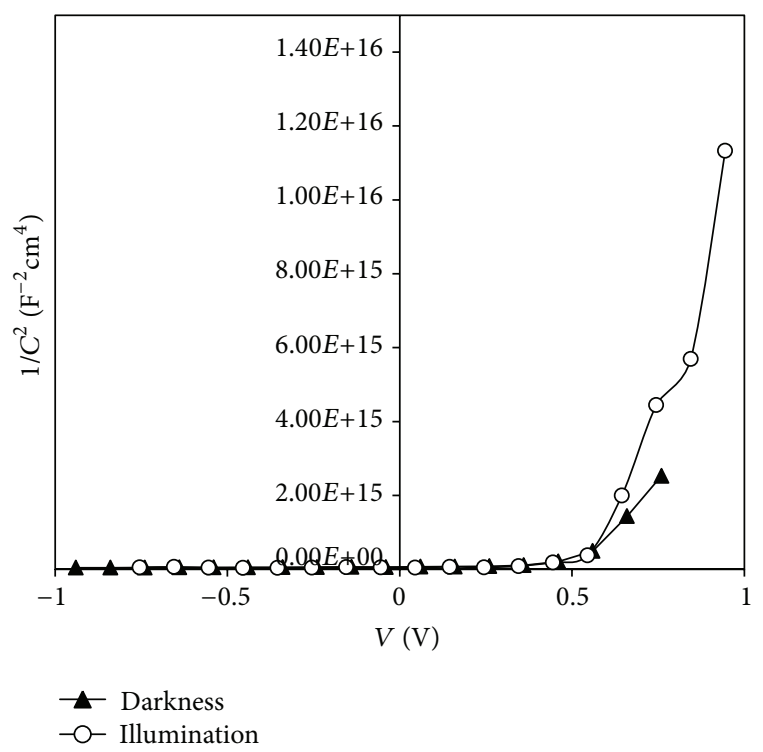

Figure 5: $C$ - $V$ curves of ITO/EB-MWCNT/ZnO-rhodamine B/ITO structure under darkness and illumination.

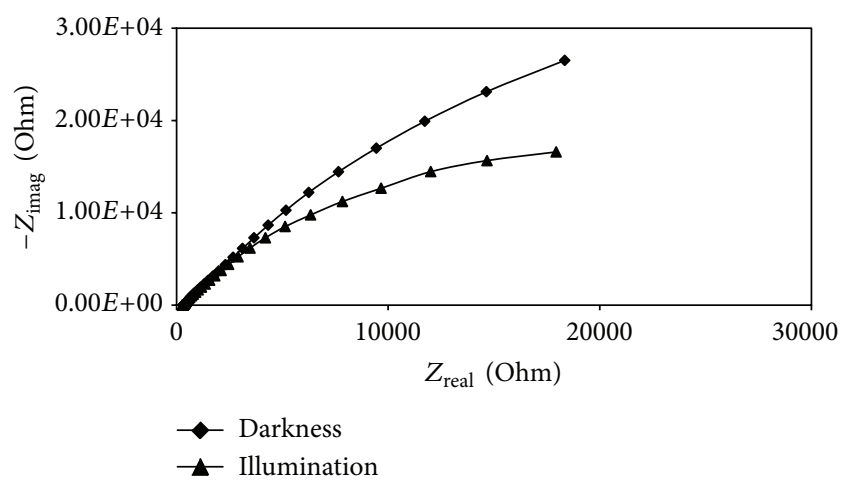

Figure 6: Nyquist curves of ITO/EB-MWCNT/ZnO-riboflavin/ ITO structure in darkness and illumination.

Nequist impedance spectra of ITO/EB-MWCNT/ZnOriboflavin/ITO and ITO/EB-MWCNTs/ZnO-rhodamine $\mathrm{B} / \mathrm{ITO}$ structures under darkness and illumination with electrolytes (shown in Figures 6 and 7) at $0.0 \mathrm{~V}$ are nearly a semicircle, indicating the predominance of a single time constant. The shunt resistances of ITO/EB-MWCNT/ZnOriboflavin/ITO are in the order of 60 and $40 \mathrm{k} \Omega$ under darkness and illumination, respectively, which indicate that the efficiency of this type of solar cell is limited by a small value of the shunt resistance. The shunt resistance significantly decreases by increasing the illumination intensity. This can be explained by the presence of the leakage paths, which are physically due to generation-recombination currents within the depletion region [29]. In addition, the high series resistances of this DSSC are 332 and $291 \Omega$ under darkness and illumination, respectively. The shunt resistances of ITO/EBMWCNT/ZnO-rhodamine B/ITO are in the order of 100 and $20 \mathrm{k} \Omega$ under darkness and illumination, respectively. In

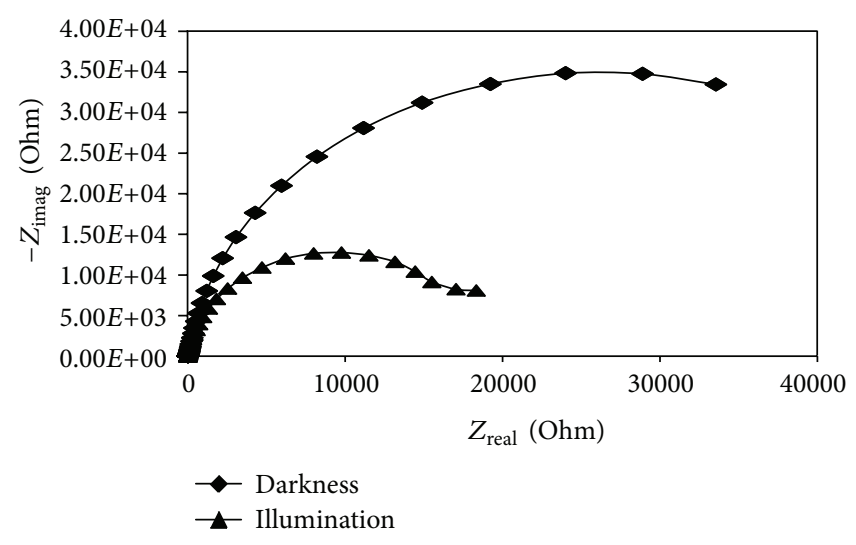

Figure 7: Nyquist curves of ITO/EB-MWCNT/ZnO-rhodamine $\mathrm{B} / \mathrm{ITO}$ structure in darkness and illumination.

addition, the series resistances of this DSSC are 62 and $60 \Omega$ under darkness and illumination, respectively.

\section{Conclusion}

In this study, it was found that a dye-sensitized solar cell based on the composites of EB-MWCNTs and $\mathrm{ZnO}$ sensitized with rhodamine B had a higher performance than riboflavin. The highest photovoltaic cell characteristics, that is, $V_{\mathrm{oc}}, J_{\mathrm{sc}}$, and $\eta$, were found to be $0.48 \mathrm{~mA} / \mathrm{cm}^{2}, 400 \mathrm{mV}$, and $0.224 \%$, respectively, for ITO/EB-MWCNTs/ZnO-rhodamine B/ITO heterostructure. Using impedance spectra, it was found that the series resistances of this type of solar cell are 62 and $60 \Omega$ under darkness and illumination, respectively. On the other hand, the high series resistances of ITO/EB-MWCNT/ZnOriboflavin/ITO DSSC are 332 and $291 \Omega$ under darkness and illumination, respectively.

\section{References}

[1] I. Morsi, S. Ebrahim, and M. Soliman, "Construction and Study of Hetreojunction Solar Cell Based on Dodecylbenzene Sulfonic Acid-Doped Polyaniline/n-Si," International Journal of Photoenergy, vol. 2012, Article ID 917020, 6 pages, 2012.

[2] H. Dai, J. H. Hafner, A. G. Rinzler, D. T. Colbert, and R. E. Smalley, "Nanotubes as nanoprobes in scanning probe microscopy," Nature, vol. 384, no. 6605, pp. 147-150, 1996.

[3] W. B. Choi, D. S. Chung, J. H. Kang et al., "Fully sealed, highbrightness carbon-nanotube field-emission display," Applied Physics Letters, vol. 75, no. 20, pp. 3129-3131, 1999.

[4] C. Liu, Y. Y. Fan, M. Liu, H. T. Cong, H. M. Cheng, and M. S. Dresselhaus, "Hydrogen storage in single-walled carbon nanotubes at room temperature," Science, vol. 286, no. 5442, pp. 1127-1129, 1999.

[5] P. J. de Pablo, E. Graugnard, B. Walsh, R. P. Andres, S. Datta, and R. Reifenberger, "A simple, reliable technique for making electrical contact to multiwalled carbon nanotubes," Applied Physics Letters, vol. 74, no. 2, pp. 323-325, 1999.

[6] Y. Y. Wei and G. Eres, "Directed assembly of carbon nanotube electronic circuits," Applied Physics Letters, vol. 76, no. 25, pp. 3759-3761, 2000. 
[7] T. Abdel-Fattah, E. J. Siochi, and R. E. Crooks, "Pyrolytic synthesis of carbon nanotubes from sucrose on a mesoporous silicate," Fullerenes Nanotubes and Carbon Nanostructures, vol. 14, no. 4, pp. 585-594, 2006.

[8] S. Berson, R. De Bettignies, S. Bailly, S. Guillerez, and B. Jousselme, "Elaboration of P3HT/CNT/PCBM composites for organic photovoltaic cells," Advanced Functional Materials, vol. 17, no. 16, pp. 3363-3370, 2007.

[9] S. AbdulAlmohsin, Z. Li, M. Mohammed, K. Wu, and J. Cui, "Electrodeposited polyaniline/multi-walled carbon nanotube composites for solar cell applications," Synthetic Metals, vol. 162, pp. 931-935, 2012.

[10] G. Wang, W. Xing, and S. Zhuo, "The production of polyaniline/graphene hybrids for use as a counter electrode in dyesensitized solar cells," Electrochimica Acta, vol. 66, pp. 151-157, 2012.

[11] Y. Xiao, J. Lin, W. Wang, S. Tai, G. Yue, and J. Wu, "Enhanced performance of low-cost dye-sensitized solar cells with pulse-electropolymerized polyaniline counter electrodes," Electrochimica Acta, vol. 90, pp. 468-474, 2013.

[12] Y. Xiao, J. Lin, J. Wu, S. Tai, G. Yue, and T. Lin, "Dyesensitized solar cells with high-performance polyaniline/multiwall carbon nanotube counter electrodes electropolymerized by a pulse potentiostatic technique," Journal of Power Sources, vol. 233, pp. 320-325, 2013.

[13] T. M. Abdel-Fattah, S. Ebrahim, M. Soliman, and M. Hafez, "Dye-sensitized solar cells based on polyaniline-single waller carbon nanotubes composite," ECS Journal of Solid State Science and Technology, vol. 2, pp. M13-M16, 2013.

[14] J. H. Jun, K. Cho, J. Yun, K. S. Suh, T. Kim, and S. Kim, "Enhancement of electrical characteristics of electrospun polyaniline nanofibers by embedding the nanofibers with Gadoped $\mathrm{ZnO}$ nanoparticles," Organic Electronics, vol. 9, no. 4, pp. 445-451, 2008.

[15] M. Stacey, C. Osgood, B. S. Kalluri, W. Cao, H. Elsayed-Ali, and T. Abdel-Fattah, "Nanosecond pulse electrical fields used in conjunction with multi-wall carbon nanotubes as a potential tumor treatment," Biomedical Materials, vol. 6, no. 1, Article ID 011002, 2011.

[16] S. Ebrahim, M. Soliman, and T. M. Abdel-Fattah, "Hybrid inorganic-organic heterojunction solar cell," Journal of Electronic Materials, vol. 40, no. 9, pp. 2033-2041, 2011.

[17] S. M. Ebrahim, "Fabrication of Schottky diode based on Zn electrode and polyaniline doped with 2-acrylamido-2-methyl-1propanesulfonic acid sodium salt," Journal of Polymer Research, vol. 16, no. 5, pp. 481-487, 2009.

[18] W. J. Spetnagel and I. M. Klotz, "Oxidation of dihydronicotinamide adenine dinucleotide by a flavin derivative of polyethylenimine," Biopolymers, vol. 17, no. 7, pp. 1657-1668, 1978.

[19] Y. Tachibana, S. A. Haque, I. P. Mercer, J. R. Durrant, and D. R. Klug, "Electron injection and recombination in dye sensitized nanocrystalline titanium dioxide films: a comparison of ruthenium bipyridyl and porphyrin sensitizer dyes," Journal of Physical Chemistry B, vol. 104, no. 6, pp. 1198-1205, 2000.

[20] E. Kymakis and G. A. J. Amaratunga, "Carbon nanotubes as electron acceptors in polymeric photovoltaics," Reviews on Advanced Materials Science, vol. 10, no. 4, pp. 300-305, 2005.

[21] E. Kymakis and G. A. J. Amaratunga, "Single-wall carbon nanotube/conjugated polymer photovoltaic devices," Applied Physics Letters, vol. 80, no. 1, pp. 112-114, 2002.
[22] A. Luque and S. Hegedus, Handbook of Photovoltaic Science and Engineering, John Wiley \& Sons, 2003.

[23] M. Burgelman, P. Nollet, and S. Degrave, "Modelling polycrystalline semiconductor solar cells," Thin Solid Films, vol. 361-362, pp. 527-532, 2000.

[24] D. Chirvase, Z. Chiguvare, M. Knipper, J. Parisi, V. Dyakonov, and J. C. Hummelen, "Temperature dependent characteristics of poly(3 hexylthiophene)-fullerene based heterojunction organic solar cells," Journal of Applied Physics, vol. 93, no. 6, pp. 3376-3383, 2003.

[25] E. H. Rhoderic and R. H. Williams, Metals Semiconductor Contacts, Oxford University Press, 2nd edition, 1988.

[26] G. Friesen, E. D. Dunlop, and R. Wendt, "Investigation of CdTe solar cells via capacitance and impedance measurements," Thin Solid Films, vol. 387, no. 1-2, pp. 239-242, 2001.

[27] A. Straub, R. Gebs, H. Habenicht et al., "Impedance analysis: a powerful method for the determination of the doping concentration and built-in potential of nonideal semiconductor pn diodes," Journal of Applied Physics, vol. 97, no. 8, Article ID 083703, 2005.

[28] H. Bayhan and S. Ozden, "Measurement and comparison of complex impedance of silicon $p$ - $i-n$ photodiodes at different temperatures," Semiconductors, vol. 41, no. 3, pp. 353-356, 2007.

[29] H. Bayhan and A. S. Kavasoǧlu, "Admittance and impedance spectroscopy on $\mathrm{Cu}(\mathrm{In}, \mathrm{Ga}) \mathrm{Se}_{2}$ solar cells," Turkish Journal of Physics, vol. 27, no. 6, pp. 529-535, 2003. 

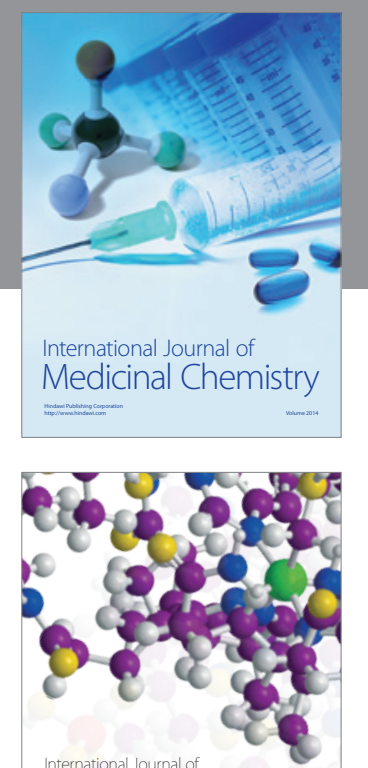

\section{Carbohydrate} Chemistry

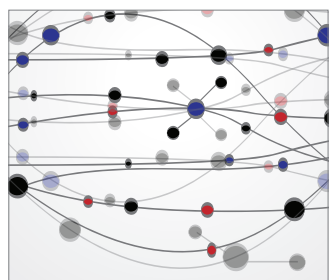

The Scientific World Journal
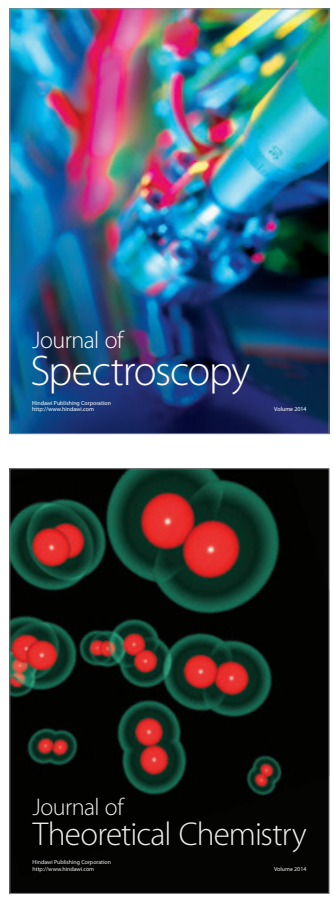
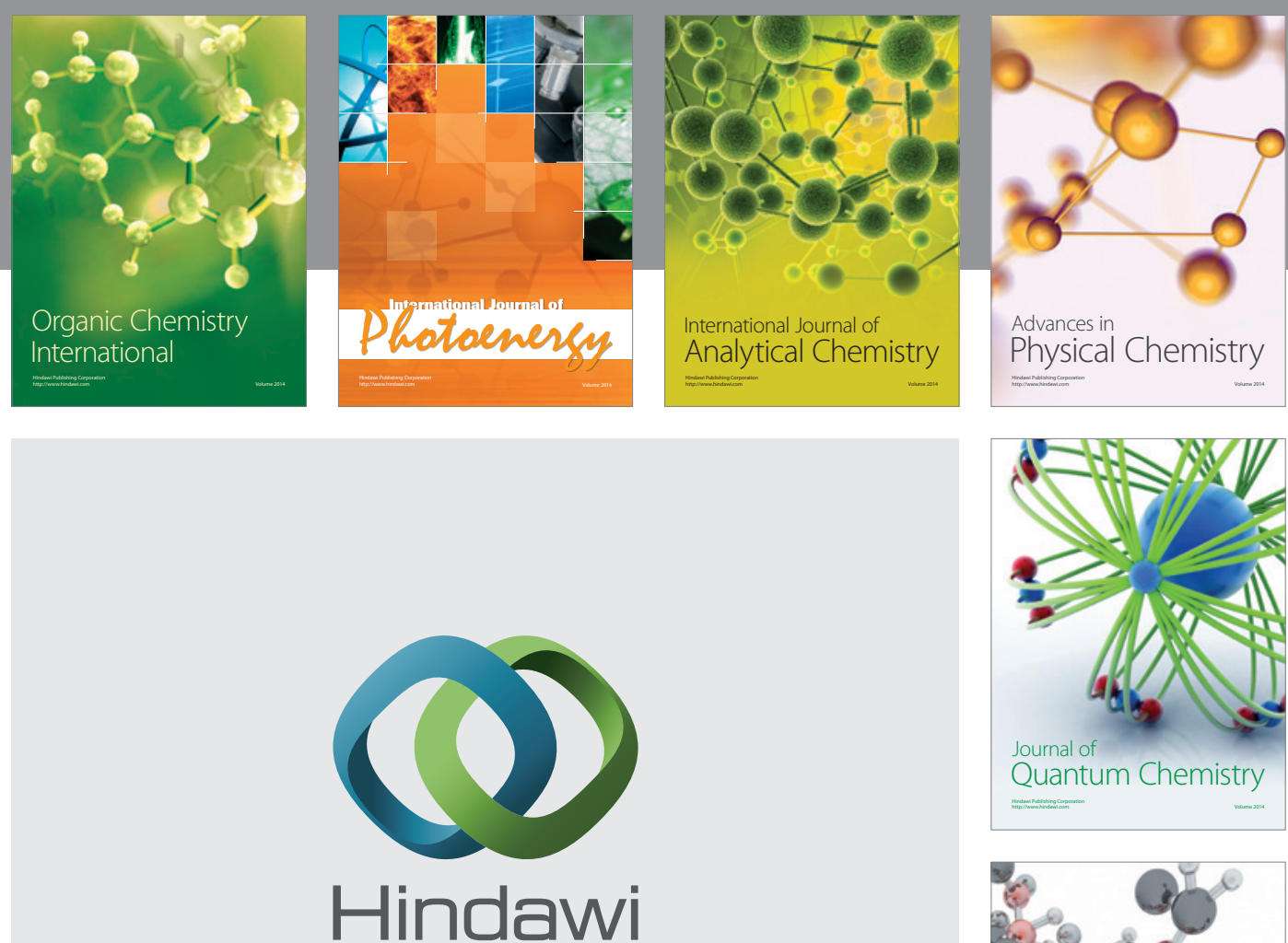

Submit your manuscripts at

http://www.hindawi.com

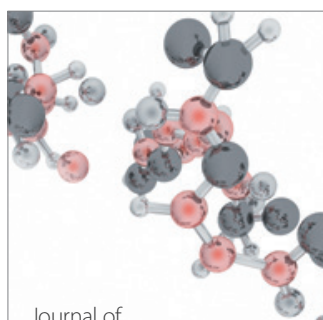

Analytical Methods

in Chemistry

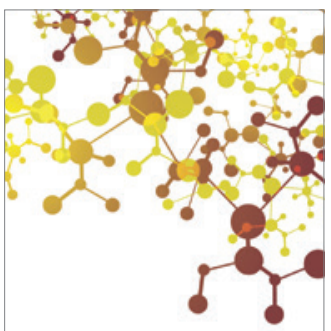

Journal of

Applied Chemistry

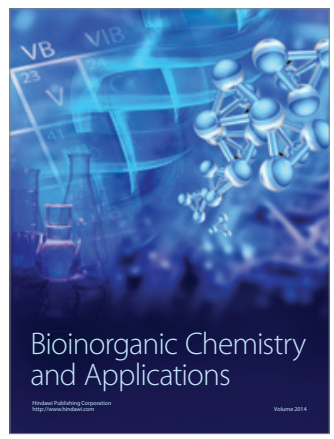

Inorganic Chemistry
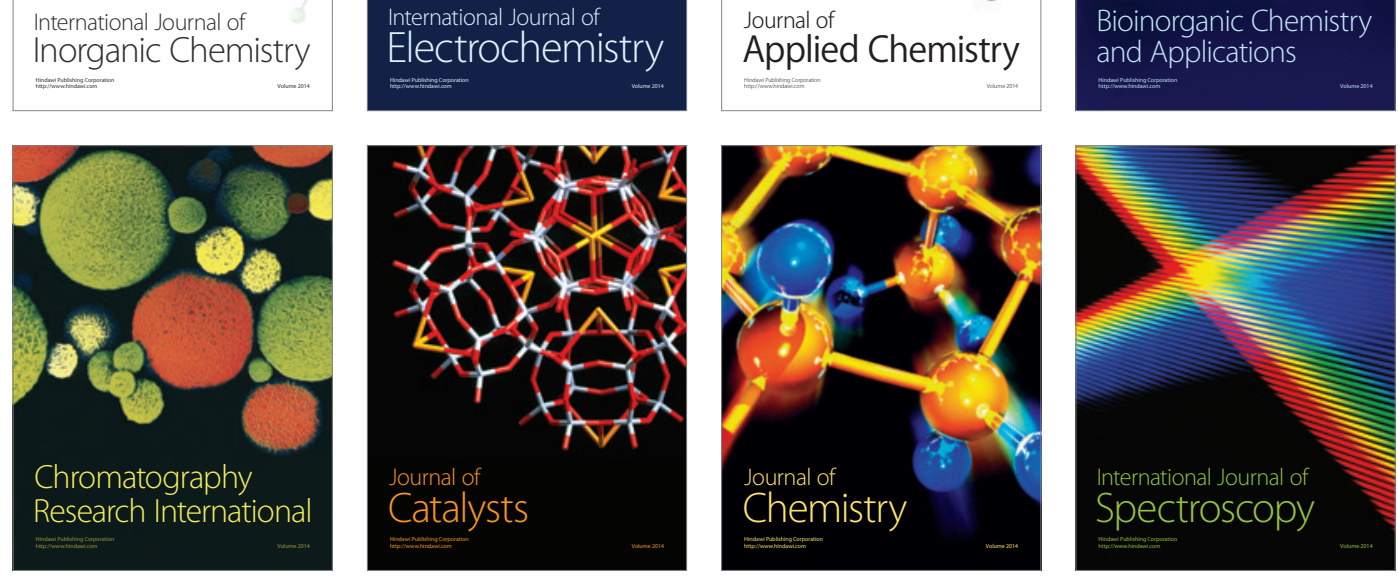